\title{
Cost-benefit of implementing a participatory extension model for improving on-farm adoption of Johne's disease control recommendations
}

\author{
S. M. Roche, ${ }^{1,2} \odot$ M. Von Massow, ${ }^{3}$ D. Renaud, ${ }^{1,2} \odot$ D. A. Shock, ${ }^{2} \odot$ A. Jones-Bitton, ${ }^{1} \odot$ and D. F. Kelton ${ }^{1 *} \odot$ \\ ${ }^{1}$ Department of Population Medicine, University of Guelph, 50 Stone Road East, Guelph, ON, Canada N1G 2W1 \\ ${ }^{2}$ Agricultural Communications and Epidemiological Research (ACER) Consulting, 103A-100 Stone Road West, Guelph, ON, Canada N1G 5L3 \\ ${ }^{3}$ Department of Food, Agricultural, and Resource Economics Guelph, 50 Stone Road East, Guelph, ON, Canada N1G 2W1
}

\section{ABSTRACT}

The objective of this study was to perform a costbenefit analysis (CBA) of a participatory extension model, called Ontario Focus Farms (FF), which was designed to facilitate the adoption of on-farm management practices to control Johne's disease (JD) on Ontario (ON) dairy farms. Partial budget models were developed to estimate the annual herd cost of JD on an average 78-cow Ontario dairy herd and the annual herd cost of neonatal calf diarrhea (NCD). With these estimates, a CBA was developed to assess the simulated net benefits of implementing various on-farm management scenarios (i.e., implementing 1, 2, or 3 of the following: calf feeding, maternity pen management, maternity area structure changes), where the benefits represent a reduction in the annual cost of JD and NCD. These models informed the final CBA assessing the net benefits of FF implementation over a 10-yr period. All monetary values are reported in Canadian dollars (Can $\$$; where 1 Can $\$=0.823$ US $\$$ at the time of the study). The annual herd cost of JD was estimated to be $\$ 3,242$ ( $\$ 41.56 / \mathrm{cow})$, and that of NCD was estimated to be $\$ 1,390$ ( $\$ 36 /$ heifer calf). When farms were expected to have both JD and NCD, all scenarios, when implemented over a 10-yr period, yielded positive net benefits ranging from $\$ 439$ to $\$ 2,543$ per farm when changes to maternity area structure were combined with calf feeding changes. These effects were sensitive to changes in level of disease (JD and NCD) on the farm, and the costs and effects of making changes. The NPV of making any on-farm change when JD was not present on the farm was negative. Overall, FF implementation yielded positive net benefits of $\$ 426,351$ or $\$ 749,808$, depending on whether a veterinarian or non-veterinarian served as the facilitator. The NPV was most sensitive to changes in burden of disease, the

Received March 29, 2019.

Accepted August 29, 2019.

*Corresponding author: dkelton@uoguelph.ca cost of implementing changes, and the proportion of FF participants that had JD and NCD on the farm. Benefits of FF implementation are also likely to accrue to veterinarians, as a result of professional facilitator training, and the Ontario dairy industry, as a byproduct of improved milk quality and safety; therefore, the true net benefits of FF implementation are likely underestimated. Overall, the FF process should be considered an economically viable program and worthy of investment as part of a JD control strategy, as it demonstrates potential to yield positive net benefits for the Ontario dairy industry.

Key words: Johne's disease, cost-benefit analysis, economics, dairy cattle

\section{INTRODUCTION}

Johne's disease (JD) is an important production-limiting disease affecting dairy cattle (Garcia and Shalloo, 2015; McAloon et al., 2016). In addition to decreased milk production and premature culling of subclinical animals, clinically affected animals can develop chronic diarrhea and waste away over time (Tiwari et al., 2006; McAloon et al., 2016). Canadian studies report that 10 to $60 \%$ of dairy herds have at least 2 seropositive cows (Tiwari et al., 2009; Corbett et al., 2018). Two partial budgets, monetizing the annual herd costs of JD using Canadian estimates, estimated losses of Can $\$ 2,472$ (Chi et al., 2002) and Can $\$ 2,992$ (Tiwari et al., 2008). Extrapolating these estimates to all of Canada has resulted in an estimated annual loss of over Can $\$ 15$ million for the Canadian dairy industry (McKenna et al., 2006).

With no effective treatment available, the most common approach to addressing JD is through control programs based on periodic testing of cows to identify test-positive cows and implementing management changes to improve farm biosecurity (Sweeney et al., 2012). Beginning in 2010, Ontario implemented a 3-yr rollout of a voluntary JD control program, called the Ontario Johne's Education and Management Assistance Program (OJEMAP) (OJEMAP, 2009). The program 
comprised an education component, a veterinarianadministered on-farm risk assessment, and voluntary whole-herd testing. The education component of OJEMAP focused on the development of an extension model to improve the adoption of on-farm management practices to control JD. The resulting model, Ontario Focus Farms (FF), is a self-directed, learner-centered, participatory model that aims to influence producer behavior by addressing their knowledge, attitudes, perceptions, and opinions. Results of an evaluation of the $\mathrm{FF}$ process showed that it was effective in improving participants' knowledge about JD and changing their attitude and behavior with respect to on-farm management; $81 \%$ of $\mathrm{FF}$ respondents implemented at least one on-farm management change for JD control compared with $38 \%$ of control respondents (Roche et al., 2015). Although the pilot implementation and evaluation demonstrated positive on-farm outcomes, further investment in this initiative requires a more in-depth economic evaluation.

Cost-benefit analysis (CBA) provides a framework for economically evaluating the efficacy of the FF process for JD control. Cost-benefit analysis allows future costs and benefits to be considered in present day dollars by discounting future costs and benefits to obtain the present value (PV). The PV costs and PV benefits are then subtracted to calculate the net present value (NPV), or the value of the expected future returns of an investment minus the value of the expected future costs (Boardman et al., 2010). From this perspective, costs of FF implementation mainly represent direct transactions for goods and services (e.g., meeting rooms, facilitation costs). The benefits of FF implementation accrue as a result of FF participants implementing onfarm management changes (i.e., calf feeding changes, changes to maternity pen management, maternity area structure changes), which reduce the cost of JD primarily through the prevention of new Mycobacterium avium ssp. paratuberculosis (MAP) infections and reduce the cost of neonatal calf diarrhea (NCD). The objectives of this study were to (1) develop partial budget models to estimate the annual herd cost of JD and NCD on a 78-cow dairy herd in Ontario, and (2) perform a CBA to evaluate the NPV of implementing FF in Ontario over a 10-yr period to facilitate the adoption of on-farm management practices to prevent and control JD.

\section{MATERIALS AND METHODS}

\section{General Modeling Approach}

A partial budget was first developed to estimate the annual herd cost of JD on an average Ontario dairy farm. Given that the implementation of management changes for JD control may also have indirect effects on NCD, a second partial budget was created to estimate the annual herd cost of NCD. We then developed a CBA of the implementation of 1,2 , or 3 on-farm management practices (calf feeding changes, changes to maternity pen management, maternity area structural changes) to assess the net benefits of implementing various combinations of on-farm changes to prevent the spread of JD. The final step was to use the previously calculated estimates to inform the creation of a CBA to assess the net benefits of FF implementation in the Ontario dairy industry over a 10-yr period.

For all CBA models, PV costs and PV benefits were calculated using Equations [1] and [2]:

$$
\begin{gathered}
\text { PV costs }=C_{t} /(1+r)^{t}+\ldots C_{n} /(1+r)^{n}, \\
\text { PV benefits }=B_{t} /(1+r)^{t}+\ldots B_{n} /(1+r)^{n},
\end{gathered}
$$

where $C_{t}$ and $B_{t}$ are the total costs and total benefits for each year $(\mathrm{t})$, respectively, $\mathrm{r}$ is the discount rate, and $n$ is the total number of years.

For this study, all discounting was done for a 10-yr time period. Given that a moderate to high level of uncertainty in the realization of future cash flows exists, a discount rate of $8 \%$ was used (Pillars et al., 2009). Once all PV costs and PV benefits were estimated, the NPV was calculated using Equation [3]:

$$
\mathrm{NPV}=\mathrm{PV} \text { benefits }-\mathrm{PV} \text { costs. }
$$

All partial budgets and CBA models were built in Excel 2019 for Mac (version 16.27; Microsoft Corp., Redmond, WA). All monetized estimates are reported in Canadian dollars (Can\$; where 1 Can $\$=0.823$ US $\$$ at the time of the study). Model parameters and estimates were obtained from the literature and personal communication with an expert and, where necessary, used to inform our assumptions. The specific parameters, estimates, and calculations used for all analyses are discussed in detail below.

\section{Estimating the Cost of JD and NCD}

Input parameters used for the partial budget models included industry- and herd-level characteristics, JD effects on milk production and culling, and NCD effects on treatment costs and inputs lost to calf mortality, each of which are briefly described below. A detailed explanation of the assumptions and estimates used can be found in Roche (2014, page 194) and within 
Supplemental File S1 (https://doi.org/10.3168/jds .2019-16708). Table 1 presents the arithmetic used to calculate the estimated costs based on the assumptions and estimates discussed below. Briefly, industry- and herd-level characteristics; that is, average milk price $(\$ 0.77 / \mathrm{kg})$, herd size (78 milking cows), annual number of heifer calves born (39), apparent within-herd test positive prevalence of JD (7\%), estimated true withinherd prevalence (calculated using equation [4]; 10\%), incidence of NCD (23\%), case fatality rate of NCD (6\%), and severity of NCD cases (85\% mild and $15 \%$ severe), were used to create a base model.

True within-herd prevalence $=$ $\frac{\text { Apparent prevalence }+ \text { Test specificity }-1}{\text { Test specificity }+ \text { Test sensitivity }-1}$.

JD Partial Budget. Estimates of the average milk loss among MAP-infected animals for parity groups 1, 2 , and $\geq 3$ were calculated to account for milk losses using reported findings from Sorge et al. (2011b) on milk loss among JD milk ELISA-positive cows by parity. To estimate the herd cost of suboptimal culling due to MAP infection, we assumed that MAP-infected cows had a $20 \%$ increased risk of being culled prematurely (Chi et al., 2002). Estimates of the cost of having to prematurely cull and replace a MAP-infected cow were determined using the "Cow Value" function found in the dairy herd management computer program DairyComp305 (DC305; Valley Agricultural Software, Tulare, CA). Estimates were separated based on low $(\geq 0.1$ to $<1.0)$ and high $(\geq 1.0)$ test-positive results and then averaged.

NCD Partial Budget. The cost of treating mild and severe cases of NCD, including veterinary costs and drugs administered, was assumed to be $\$ 35 / \mathrm{d}$ and $\$ 120 /$ d, respectively (K. Leslie, University of Guelph, Guelph, ON, Canada; personal communication). The average number of days calves were treated for NCD was 3 (Waltner-Toews et al., 1986). The average age of mortality of calves due to NCD was estimated to be 15 d (Windeyer, 2013). The marginal feed costs for preweaning heifers was assumed to be $\$ 3.00 / \mathrm{d}$ (K. Leslie; personal communication). The opportunity cost (sale value) of a heifer calf was assumed to be $\$ 150$.

Under these base assumptions and inputs listed above, the PV costs of JD and NCD were calculated over a 10-yr term. Levels of within-herd infection for both JD and NCD were assumed to remain fixed over the 10-yr period, to provide a conservative estimate of the PV costs of disease over this period.

\section{CBA for Implementing On-Farm Management Changes}

We assumed that producers would focus on making on-farm management changes to one or more of the following areas: (1) calf feeding, (2) maternity pen management, and (3) maternity area structure. The cost of each on-farm management change is outlined in Table 2 ; further explanation on these estimates is provided in Supplemental File S1 (https://doi.org/10.3168/jds .2019-16708).

\section{NPV of Implementing On-Farm Management Changes}

Producers were assumed to implement 1, 2, or all 3 of the management practices considered in this study over a $10-y r$ period, resulting in 7 potential implementation scenarios. Further, as the incubation period of JD is a minimum of 2 yr (Tiwari et al., 2006), we assumed that benefits did not begin accruing until 2 yr after implementation. Conversely, the effect of changes on the incidence of NCD were expected to be immediate, with annual benefits accruing for $2 \mathrm{yr}$ and then remaining fixed at the yr 2 incidence rate for the remainder of the 10-yr term. Finally, we assumed that as producers observed positive effects of the management practices on the incidence of NCD in the first year of implementation, their persistence to perform the change in the second year would improve. For calf feeding changes, persistence was assumed to increase from $90 \%$ to $95 \%$ in yr 2 , and remain at that level, whereas for maternity pen management changes, persistence was assumed to increase from $75 \%$ to $85 \%$ in yr 2 and remain at that level. The PV and NPV costs of implementing on-farm management changes, based on these parameters, are provided in Table 3.

\section{CBA for Implementing FF}

We estimated that $8 \mathrm{FF}$ groups would be held in Ontario each year. Each FF group was assumed to have 12 dairy producer participants who formally met 4 times in $1 \mathrm{yr}$, for $6 \mathrm{~h}$ each meeting. At the end of each year, it was assumed that a new group of dairy producers would begin the FF process. The implementation costs considered include start-up, recurrent, and opportunity costs. Table 4 provides additional detail on the specific cost estimates used.

The benefits of FF implementation were determined by calculating the number of $\mathrm{FF}$ participants adopting each scenario, and considering network effects (non-FF 
participants who would adopt a scenario as a result of networking with a FF participant), and the proportion of participating farms that have both JD and NCD (75\%). The arithmetic used to calculate the estimated benefits of $\mathrm{FF}$ implementation, based on these parameters, is provided in Table 5.

Table 6 provides the PV and NPV benefits of FF implementation, based on all parameters discussed above. Figure 1 presents a network diagram outlining the primary parameters (and their relationships) that formed the basis for calculating NPV of FF implementation.

\section{Sensitivity Analysis}

Sensitivity analyses were performed on the annual cost of JD, the annual cost of NCD, the NPV of each management scenario, and the NPV of FF implementation over a 10-yr period, to determine the inputs that had the greatest influence on estimates. Where applicable, the discount rate was varied from 3 to $10 \%$. All other factors were varied based on reasonable biological endpoints. Upon completion of all sensitivity analyses, tornado charts were created to provide a visual represen- tation of the sensitivity analysis by ranking them from most sensitive to least sensitive and presenting them graphically. A global sensitivity analysis was conducted to calculate "best-case" and "worst-case" scenarios, and to explore the differences in NPV that occurred from a group of changes made to model parameters. The variable groupings that were evaluated related to disease burden (prevalence of JD, incidence of NCD), effect of each management scenario (reduction in JD prevalence and incidence of NCD), and program factors (program costs, number of program participants, network effects). All primary parameters listed in Figure 1 were favorably changed to produce a best-case scenario, and then unfavorably changed to produce a worst-case scenario. All other global sensitivity analyses were conducted by changing one group of parameters favorably, and then unfavorably, and recording the NPV.

\section{RESULTS}

\section{Partial Budgets for JD and NCD}

The total economic losses attributed to JD, based on a true within-herd JD prevalence of $10 \%$ in a 78 -cow

\section{Make Change(s)}

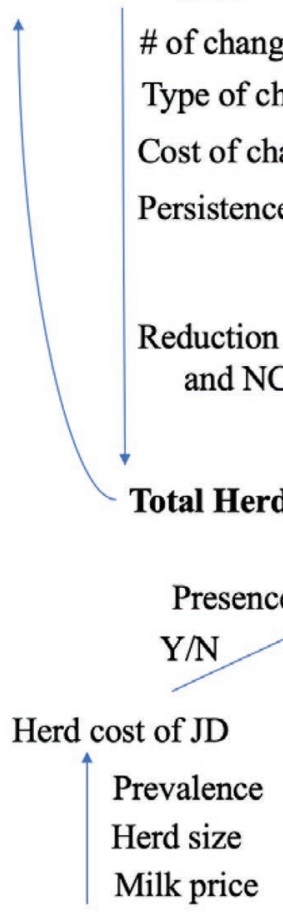

Cost of JD/case

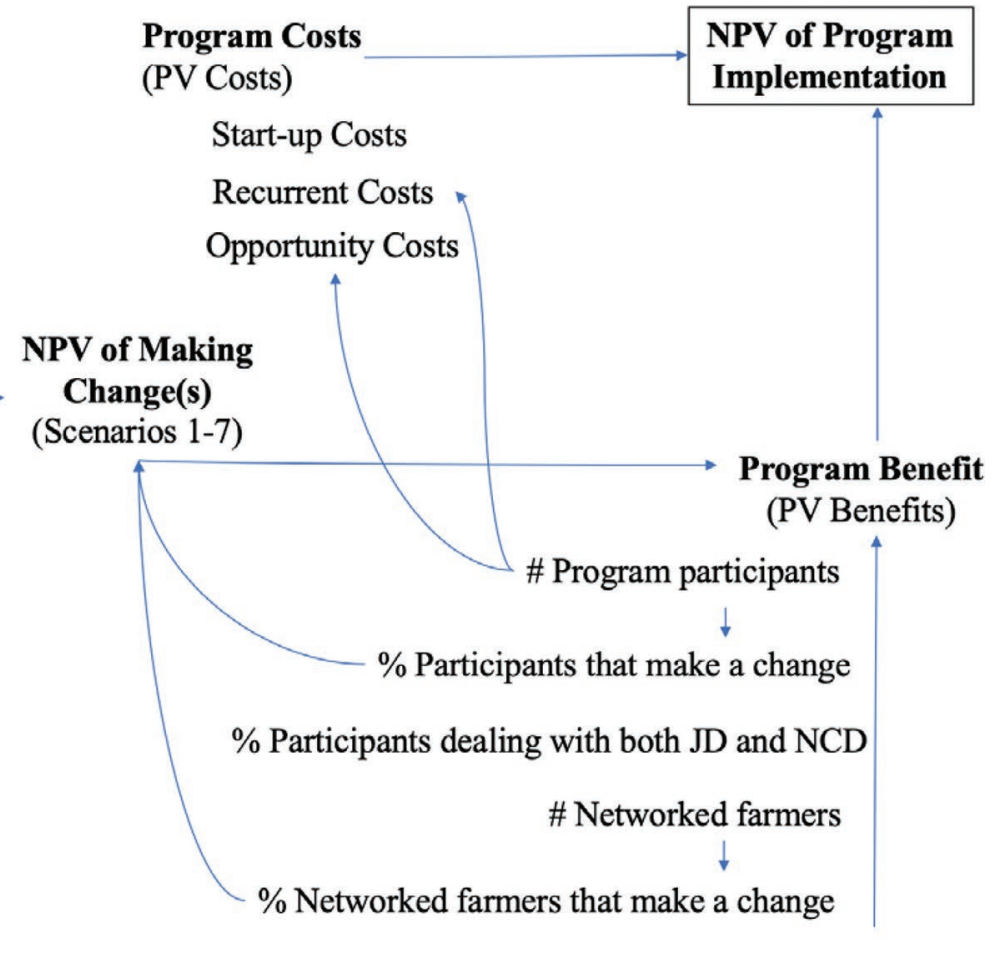

Cost of NCD/case

Figure 1. Network diagram outlining the primary parameters, and their relationships, contributing to the calculation of net present values $(\mathrm{NPV})$ for making a given management change and for program implementation. JD = Johne's disease; NCD = neonatal calf diarrhea; PV = present value. 
Roche et al.: COST-BENEFIT OF JOHNE'S DISEASE EXTENSION MODEL

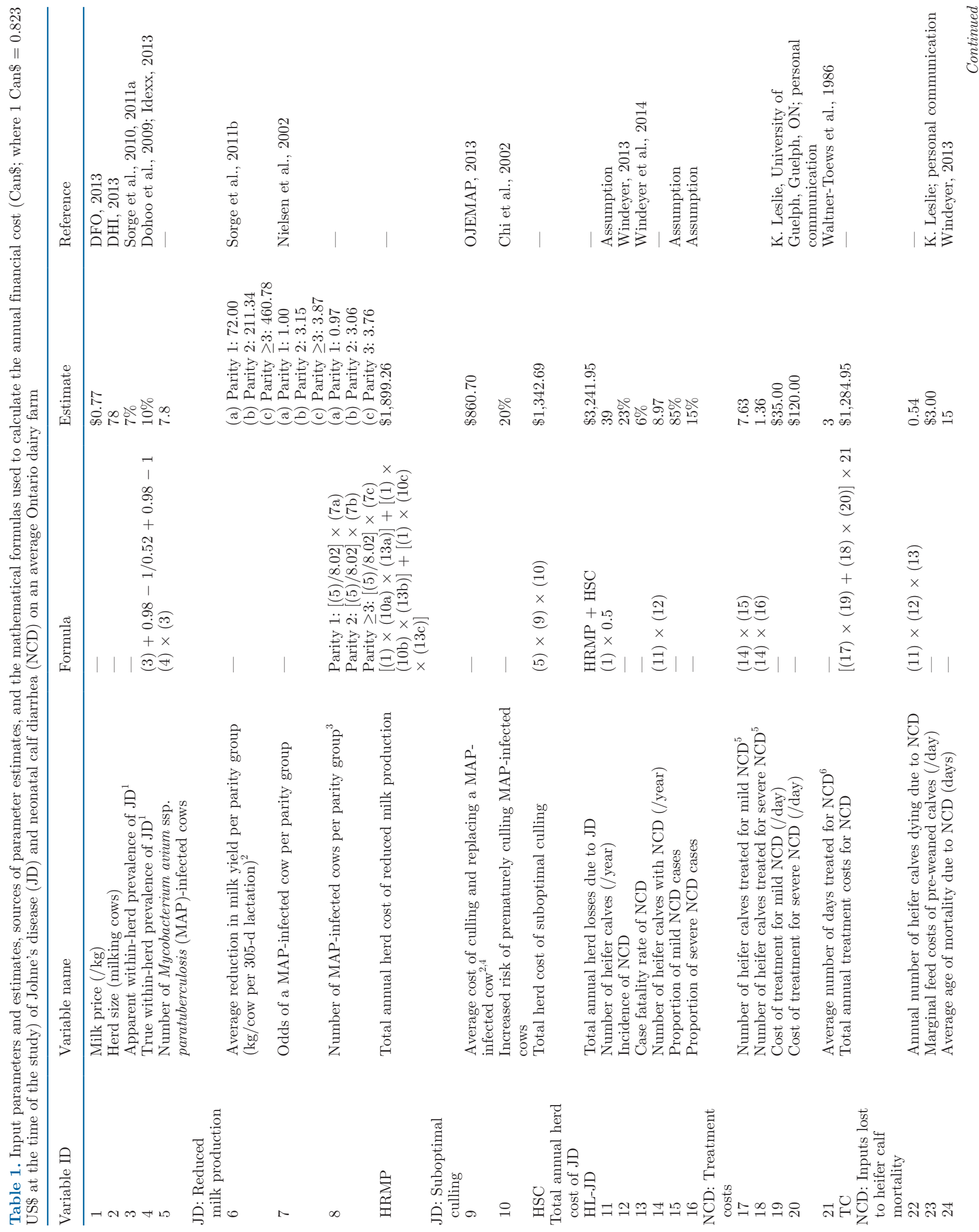


Roche et al:: COST-BENEFIT OF JOHNE'S DISEASE EXTENSION MODEL

dairy herd, were estimated to be $\$ 3,242$ annually ( $\$ 42$ / cow and \$416/MAP-infected cow). Approximately $59 \%(\$ 1,899 / \$ 3,242)$ of the total cost was attributed to reduced milk production, and the remaining $41 \%$ $(\$ 1,343 / \$ 3,242)$ was due to suboptimal culling.

The total economic losses attributed to NCD, based on a $23 \%$ incidence and $6 \%$ case fatality rate in a $78-$ cow dairy herd, were estimated to be $\$ 1,390$ annually (\$18/cow and $\$ 155 /$ sick heifer calf). Treatment of NCD represented the most significant cost, contributing $93 \%$ $(\$ 1,285 / \$ 1,390)$ of the total cost of NCD. The remaining $6 \%(\$ 81 / \$ 1,390)$ and $2 \%(\$ 24 / \$ 1,390)$ of financial losses were attributed to opportunity costs and feed costs lost to NCD mortality, respectively. Table 1 provides a breakdown of the input parameters and their values.

Of all input parameters, the estimated annual cost of JD was most sensitive to changes in true withinherd prevalence and was least sensitive to milk price and the average decrease in milk production (Figure 2). Overall, a $50 \%$ decrease in true within-herd prevalence (from $10 \%$ to $5 \%$ ) changed the annual cost from $\$ 3,242$ to $\$ 1,621$, whereas a $50 \%$ increase increased the annual cost to $\$ 4,863$.

The estimated annual cost of NCD was most sensitive to changes in the incidence of NCD and the average number of days treated, whereas cost was least sensitive to the average age of mortality due to NCD (Figure 3 ). Overall, a decrease in the incidence of NCD (from $23 \%$ to $15 \%$ ) decreased the annual cost of NCD from $\$ 1,390$ to $\$ 935$, whereas an increase to $31 \%$ increased the annual cost of NCD to $\$ 1,845$.

\section{CBA for Implementing On-Farm Management Changes}

Table 2 presents the costs incurred and the reduction in annual true within-herd prevalence of JD and annual incidence of NCD as a result of implementing on-farm management practices (calf feeding, maternity pen management, and maternity area structure) on an average, 78-cow, dairy farm in Ontario. Overall, changes to calf feeding were considered the easiest and least costly to implement ( $\$ 5 / \mathrm{cow})$, followed by maternity pen management changes $(\$ 6 / \mathrm{cow})$ and maternity area structure $(\$ 19 /$ cow $)$. The impact of each practice on reducing the true within-herd prevalence of JD, after considering persistence of each change, was highest for changes to maternity area structure $(4 \% / \mathrm{yr})$, followed by maternity pen management $(3 \% / y r)$ and calf feeding changes $(1.8 \% / y r)$. For the annual reduction in the incidence of NCD, changes to calf feeding $(13.5 \% / \mathrm{yr})$, followed by maternity area structure $(5 \% / \mathrm{yr})$ and ma- 
Roche et al.: COST-BENEFIT OF JOHNE'S DISEASE EXTENSION MODEL

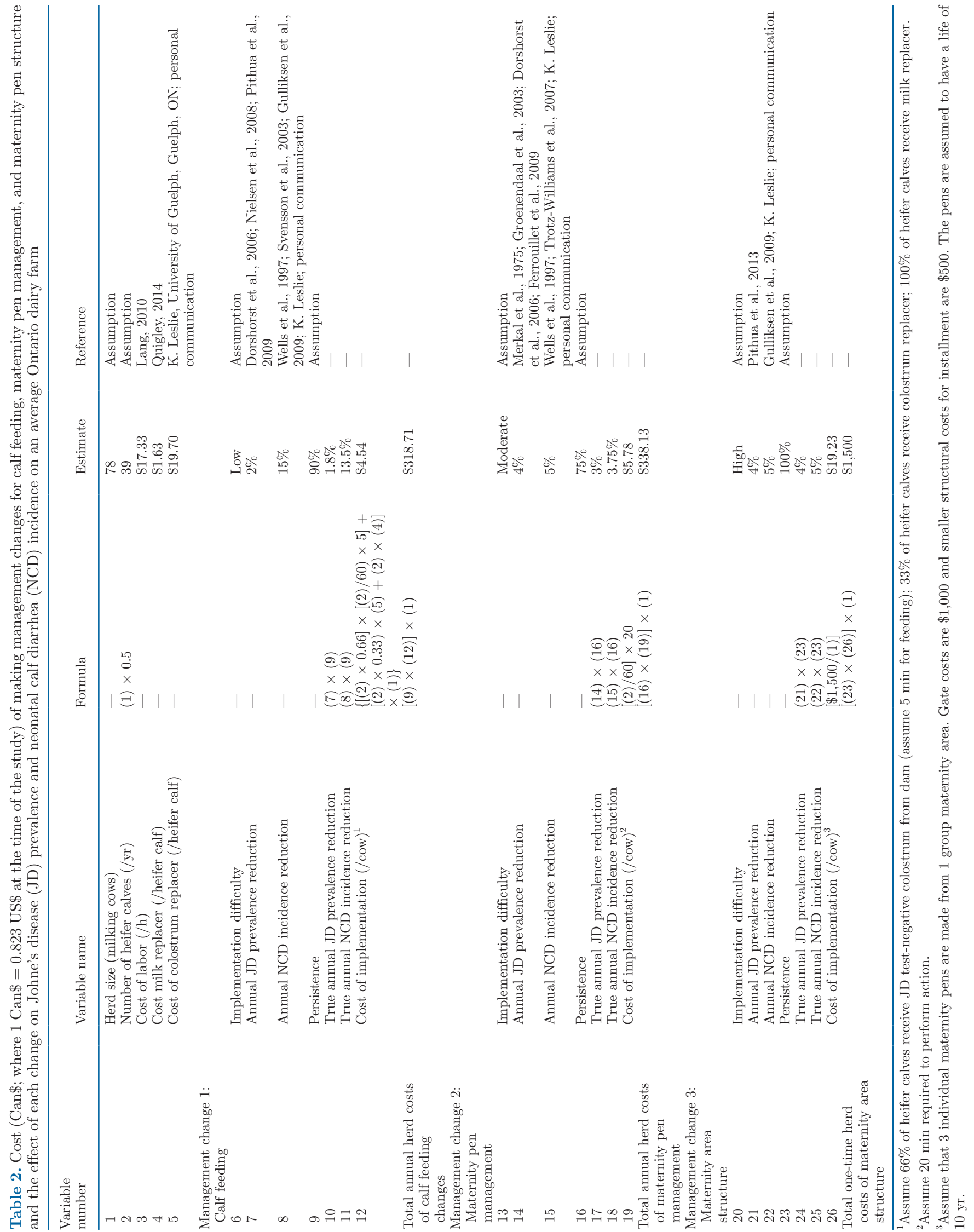


Roche et al:: COST-BENEFIT OF JOHNE'S DISEASE EXTENSION MODEL

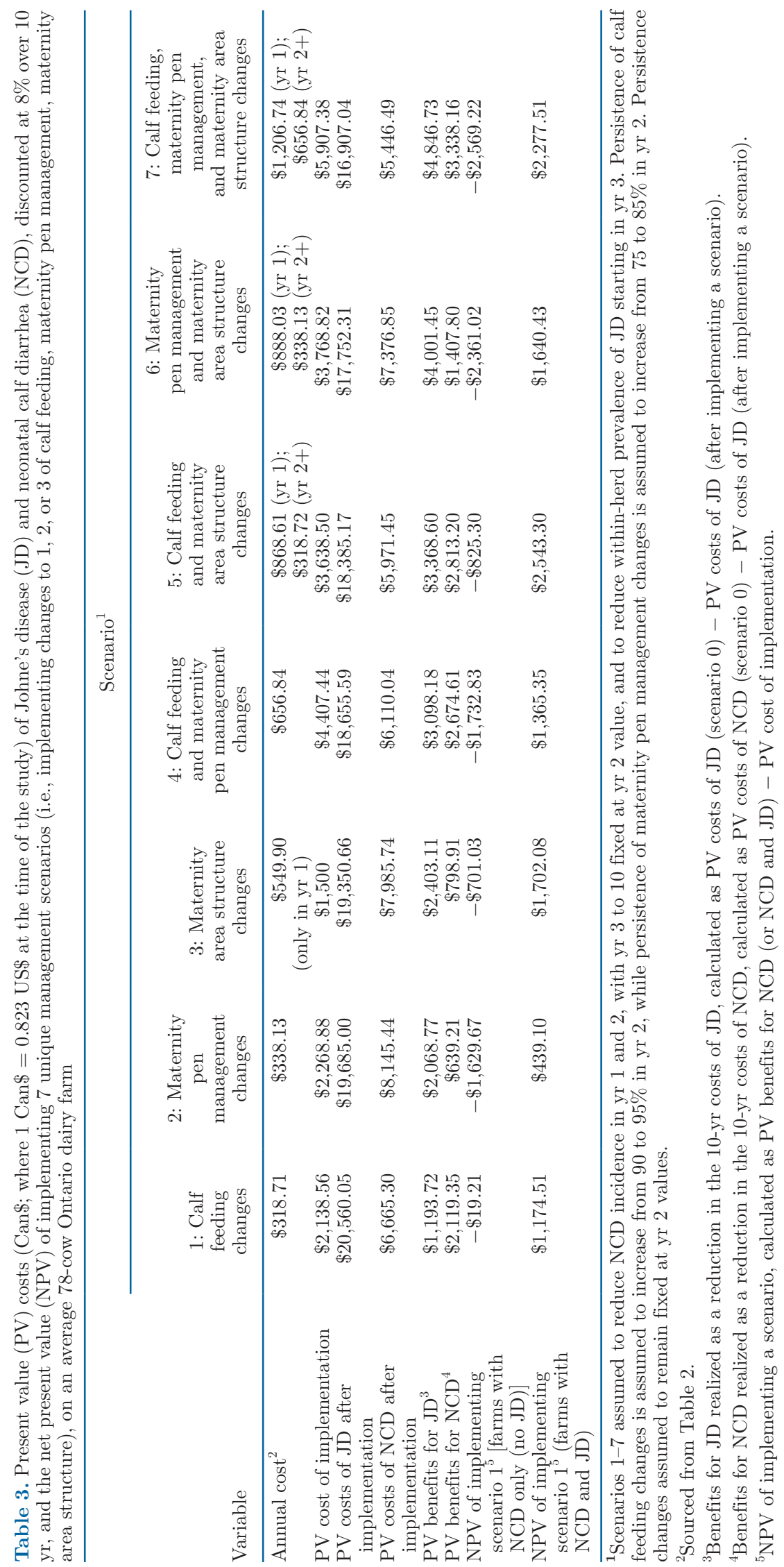


Roche et al.: COST-BENEFIT OF JOHNE'S DISEASE EXTENSION MODEL

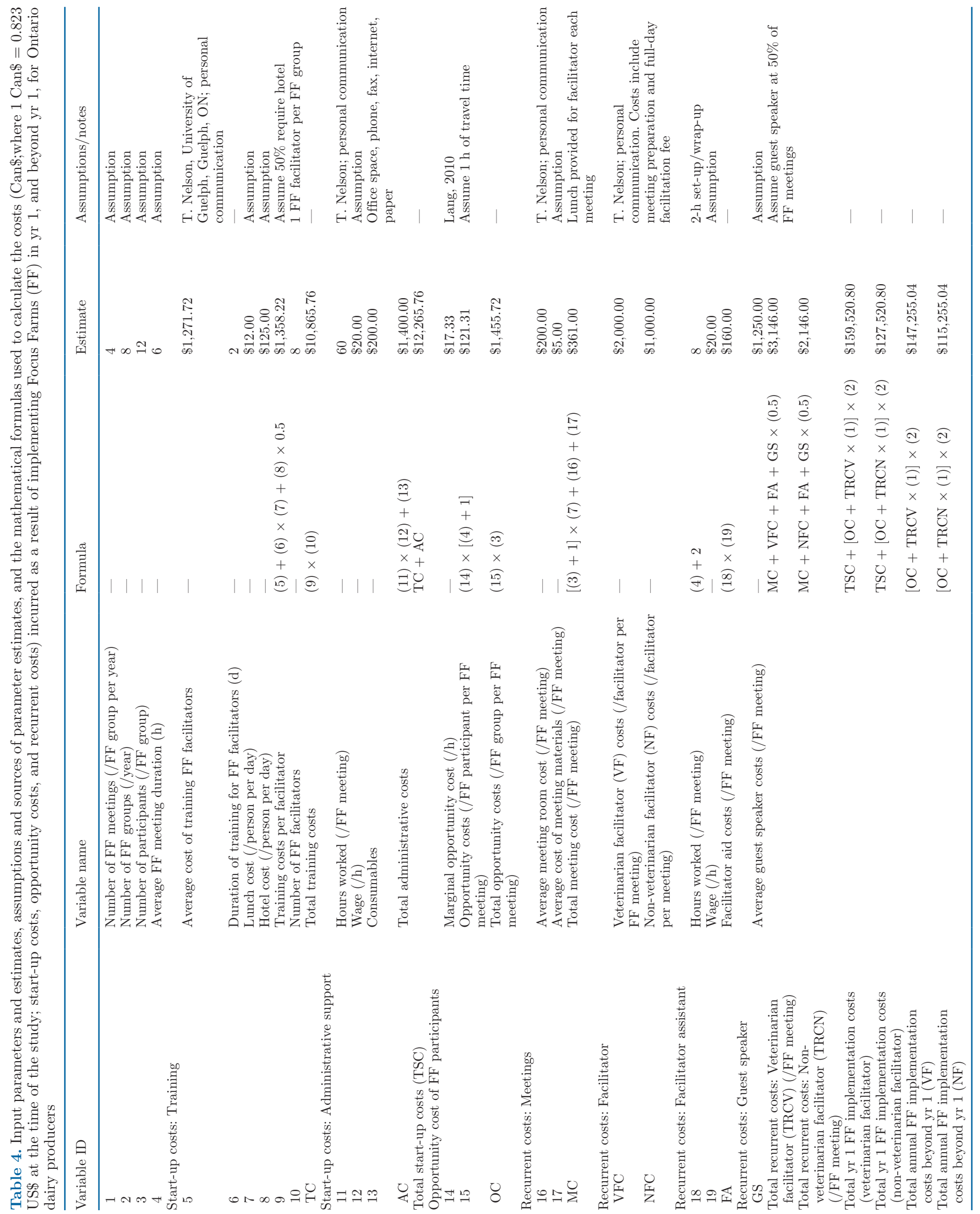


Roche et al.: COST-BENEFIT OF JOHNE'S DISEASE EXTENSION MODEL

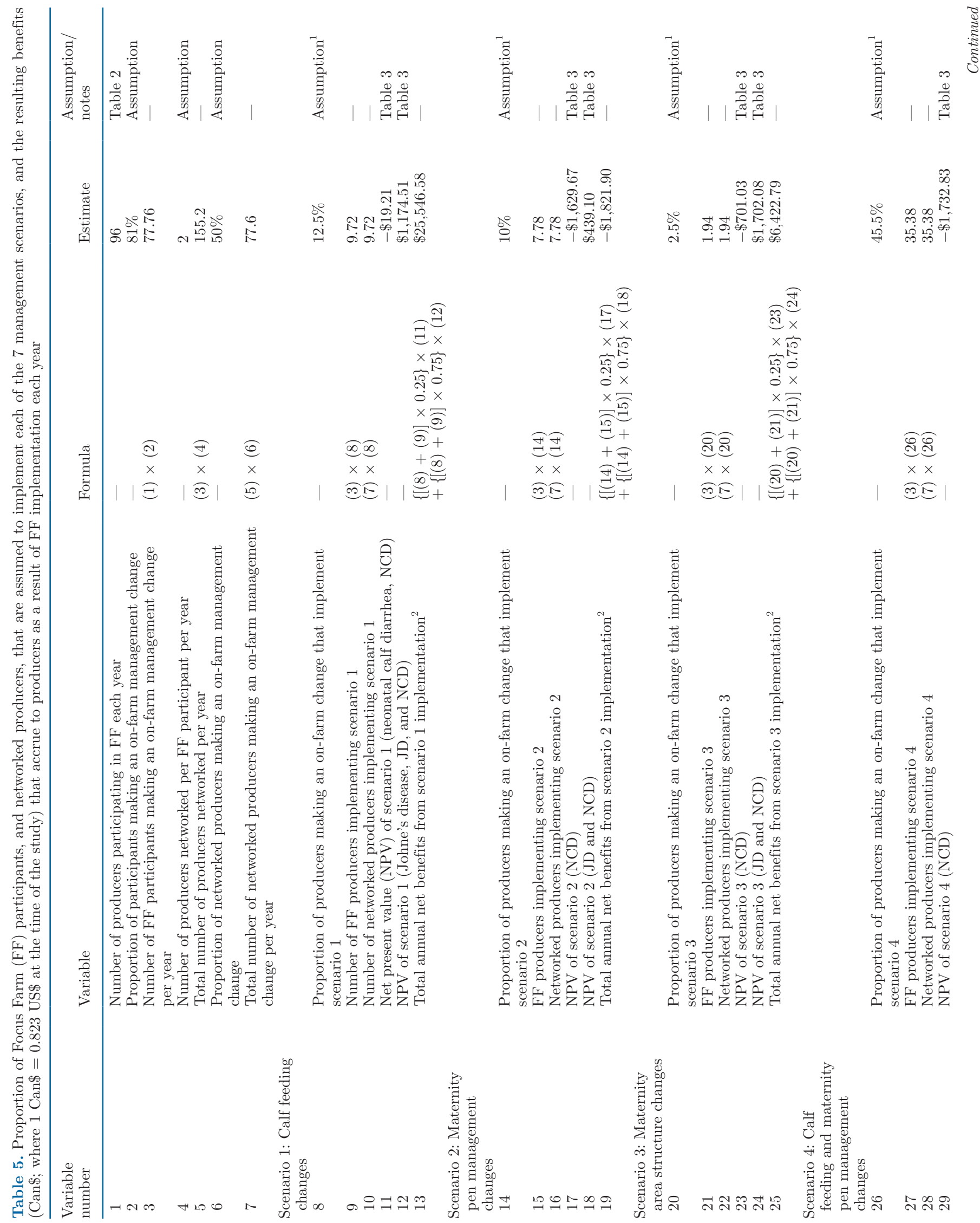


Roche et al.: COST-BENEFIT OF JOHNE'S DISEASE EXTENSION MODEL

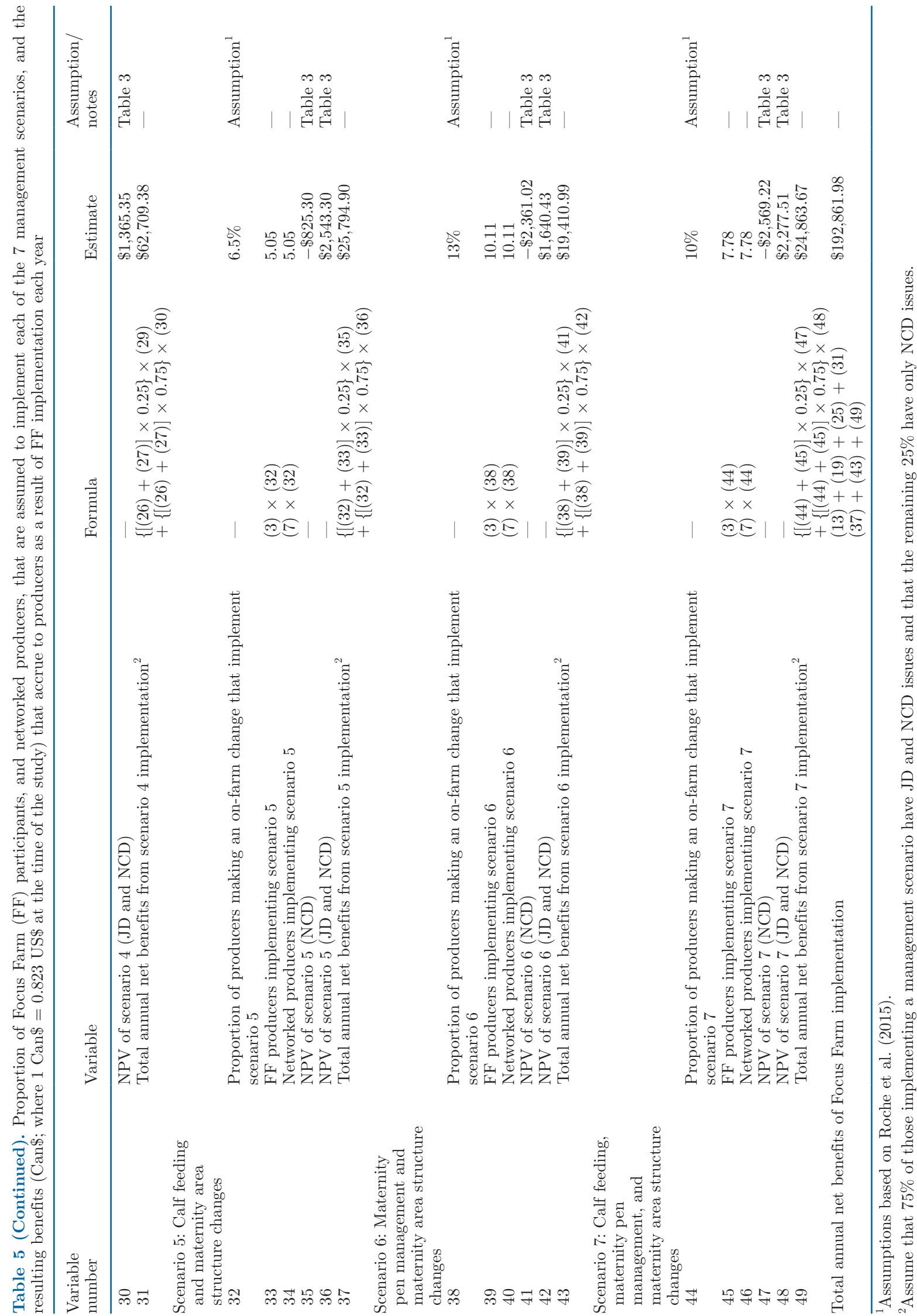


Table 6. Present value (PV) costs (Can $\$$; where 1 Can $\$=0.823$ US $\$$ at the time of the study) start-up, recurrent, and opportunity costs), PV benefits (management scenarios 1 to 7), and net present value (NPV) (PV costs - PV benefits) of implementing Focus Farms (FF), with veterinarian or non-veterinarian facilitators, for $10 \mathrm{yr}$ (discounted at $8 \%$ over a 10 -yr period)

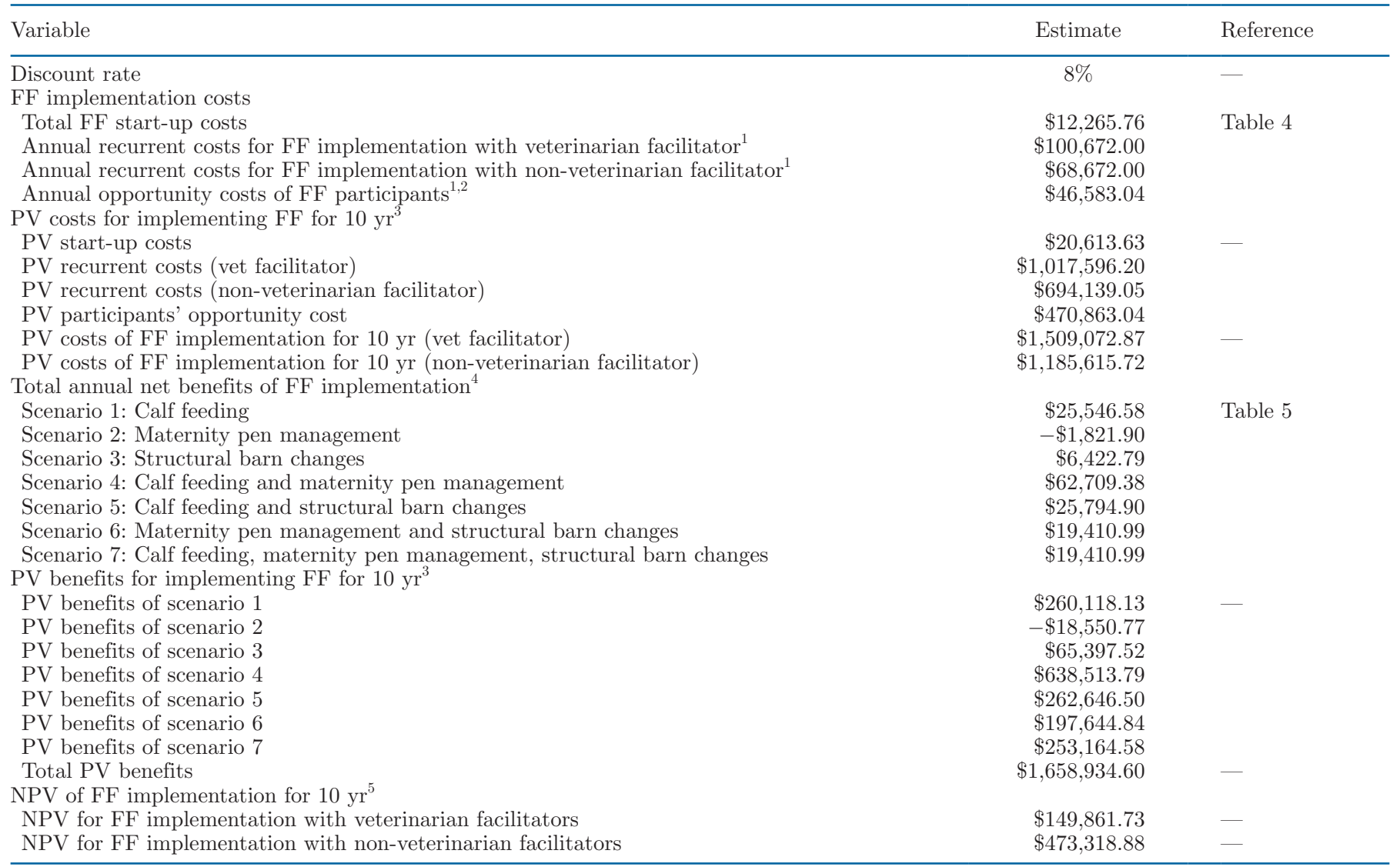

${ }^{1}$ Values calculated assuming 8 new FF groups per year, 12 FF participants per group, 4 FF meetings per group (see Table 2).

${ }^{2} \$ 121.31$ per FF participant per FF meeting (see Table 4 ).

${ }^{3}$ Assumptions: 8 new FF groups per year, 12 new FF participants per group, $4 \mathrm{FF}$ meetings per group from yr 1 to 5 . In yr 6,8 new FF facilitators are trained; 16 new FF groups per year, 12 new FF participants per group, 4 FF meetings per group from yr 6 to 10 . All PV calculations are discounted at $8 \%$ over $10 \mathrm{yr}$.

${ }^{4}$ Benefits are the NPV of implementing each management scenario over a 10 -yr period, discounted at $8 \%$. Calculated as PV benefits of management change - PV costs of implementing the management scenario. Values presented assume $81 \%$ of $\mathrm{FF}$ participants (77.76/yr) and $50 \%$ of networked producers (156/yr) implement 1 of the 7 management scenarios each year, and $75 \%$ of those that make on-farm changes have both JD and NCD (proportion of those implementing each scenario provided in Table 5).

${ }^{5} \mathrm{NPV}$ of implementing FF over a 10-yr period. Calculated as total PV benefits - PV costs of FF implementation.

ternity pen management $(3.75 \% /$ year $)$, had the greatest impact.

Table 3 provides the PV costs of JD and NCD, discounted at $8 \%$ over $10 \mathrm{yr}$, and the NPV of implementing 7 unique management scenarios on an average 78 -cow dairy farm in Ontario. For farms dealing with both JD and NCD, all 7 implementation scenarios resulted in a positive NPV, ranging from $\$ 439$ (scenario 2: maternity pen management changes) to $\$ 2,543$ (scenario 5: calf feeding and maternity area structure changes). For farms dealing with just NCD, all 7 implementation scenarios resulted in a negative NPV, ranging from $-\$ 19.21$ (scenario 1: calf feeding changes) to $-\$ 2,569$ (scenario 7: calf feeding, maternity pen management, and maternity area structure changes).

Figure 4 (a, b, c) presents tornado plots that express the sensitivity of the NPV of each individual management scenario (scenarios 1,2, and 3) to changes in the discount rate, true within-herd prevalence of JD, incidence of NCD, and the cost, effect, and persistence of each management practice, assuming the farm is dealing with both JD and NCD. The NPV of each management scenario was most sensitive to the true withinherd prevalence of JD, incidence of NCD, and the effect of specific management practices performed in each scenario. Where applicable, the NPV was also sensitive 


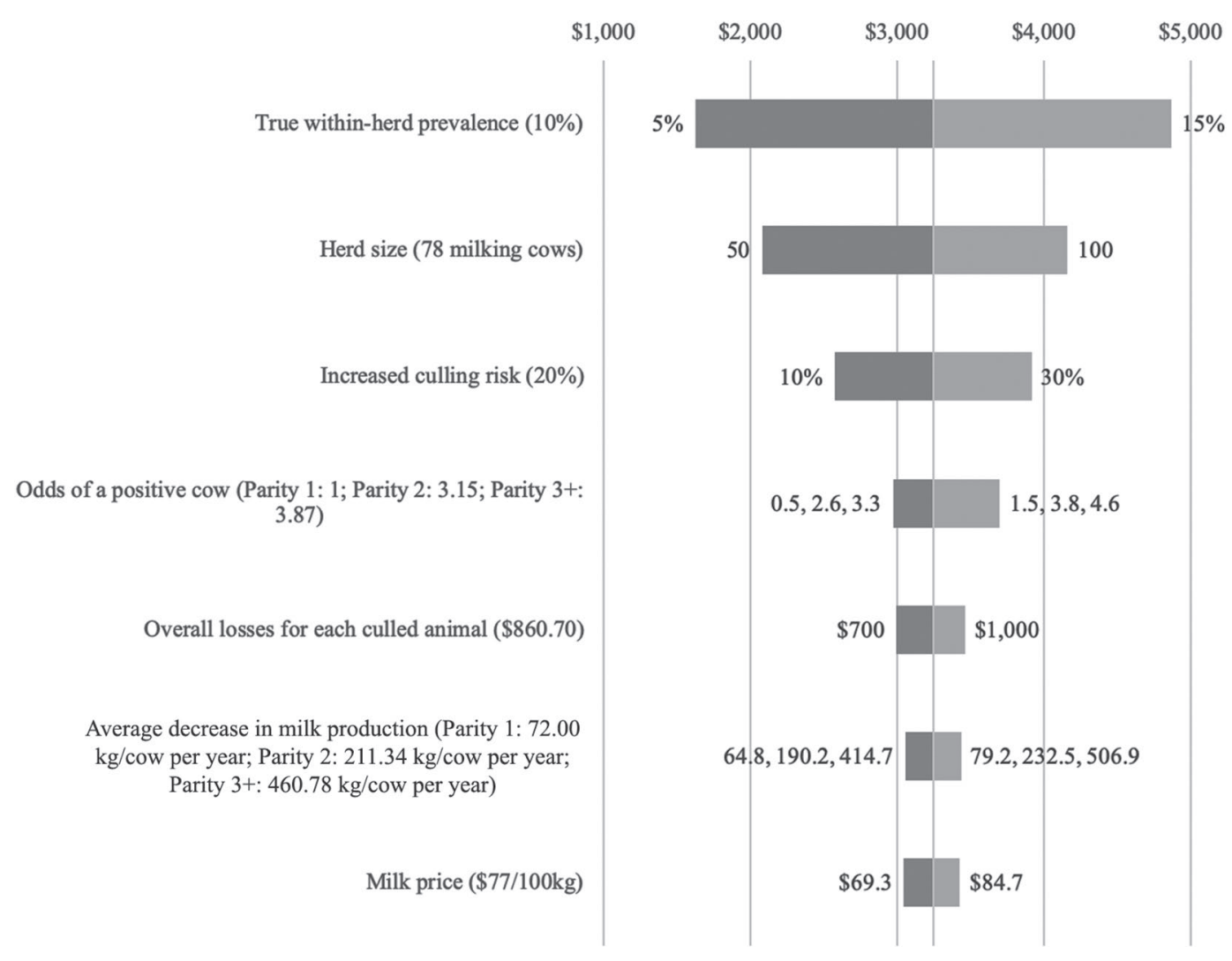

Figure 2. Tornado plot of the sensitivity of the estimated annual cost of Johne's disease (JD) on an average Ontario dairy herd (Can $\$ 3,241.95$; where 1 Can $\$=0.823$ US $\$$ at the time of the study) to changes in herd size, true within-herd prevalence, average decrease in milk production by parity group, milk price, odds of a Mycobacterium avium ssp. paratuberculosis (MAP)-infected cow by parity group, overall losses for each culled animal, and increased culling risk due to JD.

to the costs of calf feeding and maternity pen management. The NPV for all scenarios was least sensitive to the persistence of a given change and the discount rate. A reduction in the disease burden (prevalence of JD or incidence of NCD) led to negative NPV for all management scenarios. However, changes for all other management scenarios (regardless of whether they were positive or negative) resulted in positive NPV.

Figure $5(\mathrm{a}, \mathrm{b}, \mathrm{c})$ presents tornado plots that express the sensitivity of the NPV of each individual management scenario (scenarios 1, 2, and 3) to changes in the discount rate, incidence of NCD, and the cost, effect, and persistence of each management practice, assuming the farm is only dealing with NCD. The NPV of each management scenario was most sensitive to changes in the incidence of NCD and the cost and effect of the specific management practices that were being performed in each scenario. Increases in the incidence of NCD (from 23 to $31 \%$ ) resulted in a positive NPV for all scenarios. Positive NPV were also achieved when parameters were changed for calf feeding (Figure 5a); however, changes for all other management scenarios (regardless of whether they were positive or negative) resulted in negative NPV.

\section{CBA for FF Implementation}

The total implementation costs of FF in yr 1 ( $8 \mathrm{FF}$ groups, 96 participants, 4 meetings/group) were estimated to be $\$ 159,521$ and $\$ 127,521$ when using veterinarian and non-veterinarian facilitators, respectively (Table 4). With $\$ 12,266$ of start-up costs incurred in yr 1, the total annual implementation costs of FF beyond yr 1, assuming no additional FF facilitators are trained, were estimated to be $\$ 147,255$ and $\$ 115,255$ when using veterinarian and non-veterinarian facilitators, respectively.

Based on assumptions about the proportion of $\mathrm{FF}$ participants, and networked producers, that would implement each of the 7 management scenarios, the total net benefits of FF implementation in yr 1 were estimated to be $\$ 162,926$ (Table 5). Overall, 6 of the 7 management scenarios resulted in positive net benefits as a result of $\mathrm{FF}$ implementation, with the majority of 


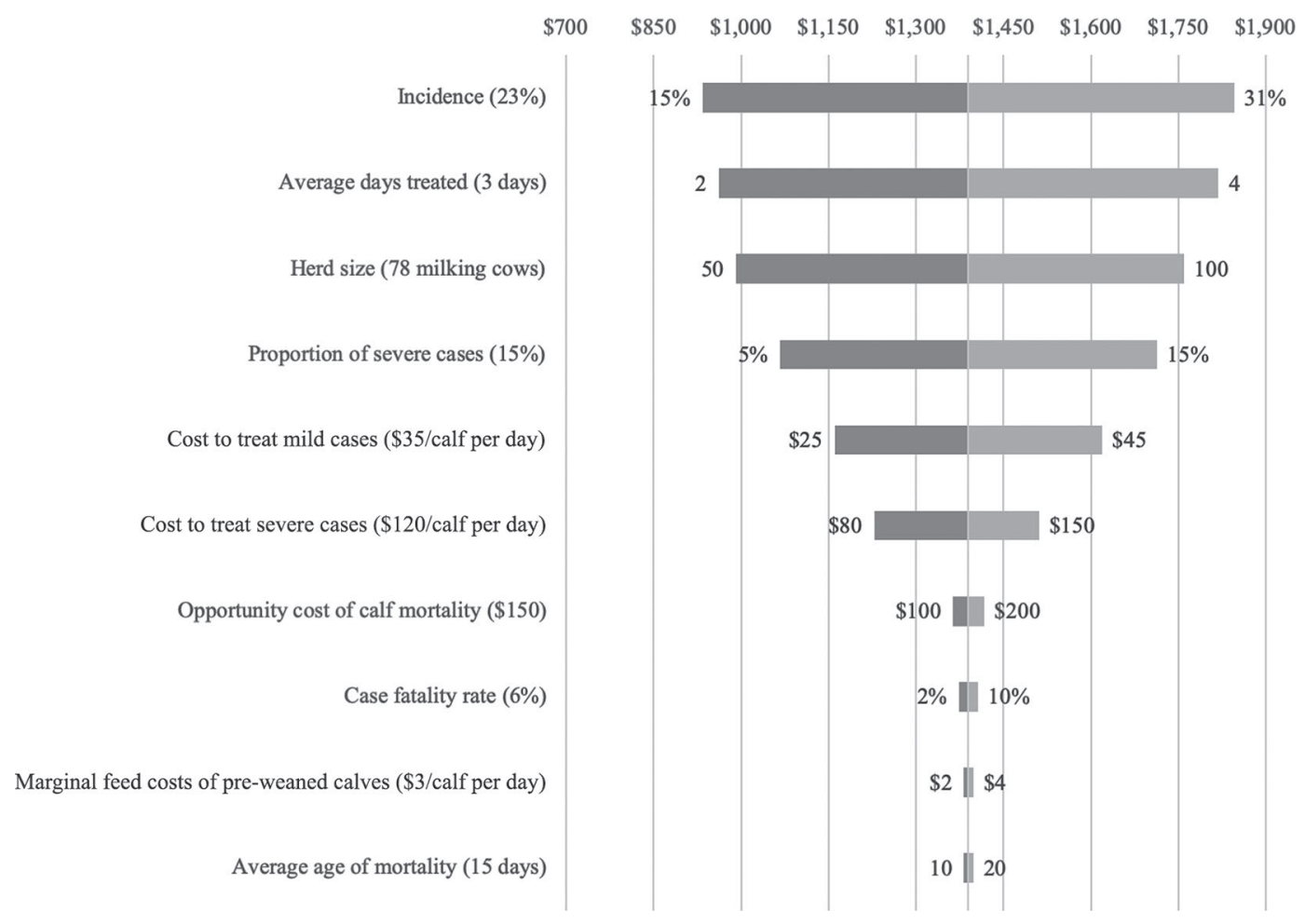

Figure 3. Tornado plot of the sensitivity of the estimated annual cost of neonatal calf diarrhea (NCD) on an average Ontario dairy herd (Can $\$ 1,389.90$; where 1 Can $\$=0.823$ US $\$$ at the time of the study) to changes in herd size, incidence, proportion of severe cases, average days treated, cost to treat mild cases, cost to treat severe cases, case fatality rate, marginal feed costs of pre-weaned calves, the average age of mortality, and the opportunity costs of mortality.

producers implementing management scenario 4 (calf feed and maternity pen management changes). However, scenario 2 (maternity pen management changes only) resulted in a loss of only $\$ 1,822$.

Table 6 presents the PV costs (start-up, recurrent, and opportunity costs), PV benefits (management scenarios 1 to 7 ), and NPV (PV costs - PV benefits) of implementing $\mathrm{FF}$, with veterinarian or non-veterinarian facilitators, for $10 \mathrm{yr}$. Overall, the implementation of $\mathrm{FF}$ with veterinarian facilitators yielded an NPV of $\$ 149,862$, whereas the implementation of FF with non-veterinarian facilitators yielded a larger NPV of $\$ 473,319$.

The estimated NPV of FF implementation, with veterinarian facilitators, was most sensitive to changes in the prevalence of JD, incidence of $\mathrm{NCD}$, and the cost of calf feeding changes; it was least sensitive to the start-up and recurrent costs of FF (Figure 6). Overall, a decrease in the prevalence of JD (10 to 5\%) decreased the NPV from $\$ 149,862$ to $-\$ 4,077,069$, whereas a within-herd prevalence of $15 \%$ increased the NPV to $\$ 4,379,069$. The estimated NPV of FF implementation with non-veterinarian facilitators was similarly sensi- tive (data not shown), with a $5 \%$ prevalence of JD reducing the NPV to $-\$ 3,562,032$, and a prevalence of $15 \%$ increasing the NPV to $\$ 5,987,228$. Global sensitivity analysis yielded a worst-case scenario (all model parameters fixed at their most unfavorable endpoint) of $-\$ 13,532,531$. Conversely, the best-case scenario would yield a NPV of $\$ 35,099,032$. Last, the program NPV was more sensitive to changes in burden of disease $(-\$ 11,232,012$ to $\$ 12,013,465)$ than to changes in the impact of each scenario $(-\$ 9,332,059$ to $\$ 10,191,893)$ and program implementation parameters $(-\$ 3,478,934$ to $\$ 3,984,431)$.

Based on the costs and assumptions above, if the total cost of FF implementation were put on the farmer, it would cost $\$ 294$ /producer per FF meeting ( $\$ 1,176$ / producer per year) and $\$ 211$ /producer per FF meeting (\$843/producer per year), when using veterinarian and non-veterinarian facilitators, respectively. Assuming a $\$ 50,000$ subsidy is obtained for FF implementation, the cost is reduced to $\$ 164$ /producer per FF meeting (\$656/producer per year) and $\$ 81 /$ producer per FF meeting (\$322/producer per year) for veterinarian and non-veterinarian facilitators, respectively. 


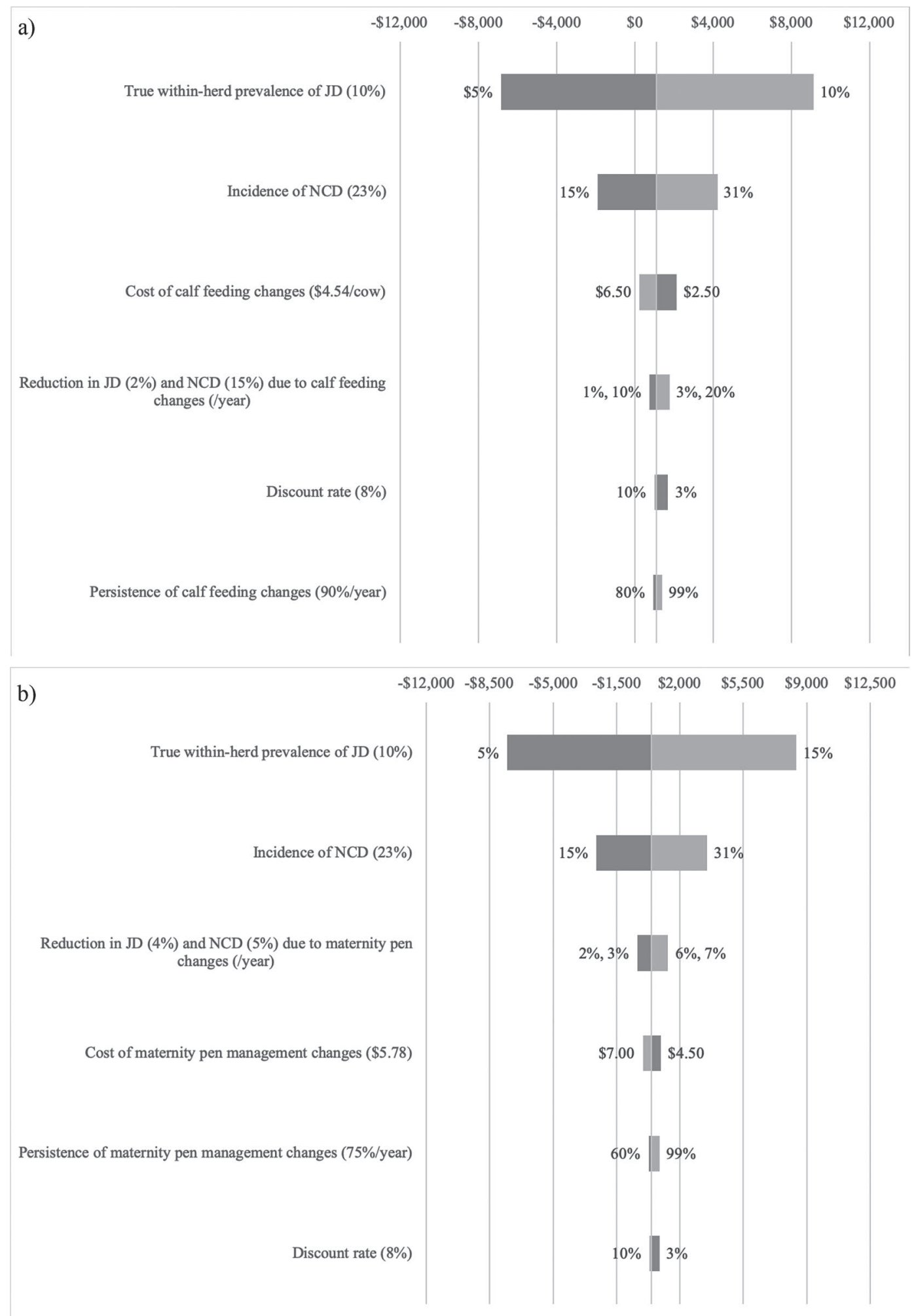

Figure 4. Tornado plot of the sensitivity of the net present value (NPV) of (a) calf feeding changes (Can $\$ 1,174.51$ ); (b) maternity pen management changes (Can $\$ 439.09$; where 1 Can $\$=0.823$ US $\$$ at the time of the study); and (c) maternity area structure changes (Can $\$ 1,702.08)$ to changes in the discount rate, true within-herd prevalence of Johne's disease (JD), incidence of neonatal calf diarrhea (NCD), and the cost, effect, and persistence of each management practice, assuming the farm is dealing with a true within-herd JD prevalence of $10 \%$ and an incidence of NCD of $23 \%$. 




Figure 4 (Continued). Tornado plot of the sensitivity of the net present value (NPV) of (a) calf feeding changes (Can $\$ 1,174.51)$; (b) maternity pen management changes (Can $\$ 439.09$; where 1 Can $\$=0.823$ US $\$$ at the time of the study); and (c) maternity area structure changes (Can\$1,702.08) to changes in the discount rate, true within-herd prevalence of Johne's disease (JD), incidence of neonatal calf diarrhea (NCD), and the cost, effect, and persistence of each management practice, assuming the farm is dealing with a true within-herd JD prevalence of $10 \%$ and an incidence of NCD of $23 \%$.

\section{DISCUSSION}

The partial budget for JD estimated the annual herd cost of JD for a 78-cow dairy farm with a true withinherd prevalence of $10 \%$, to be $\$ 3,242$. The estimate for apparent within-herd JD prevalence was obtained from data reported by Sorge et al. (2010, 2011a), which was based on the use of milk ELISA tests. Given the relatively poor sensitivity of this test (52\%), estimates of the number of MAP-infected cows and the subsequent losses associated with MAP infection would be underestimated when this estimate is used. Hence, the apparent within-herd prevalence was adjusted to estimate the true within-herd prevalence of JD. However, Tiwari et al. (2006) noted there was little consensus on the appropriate adjustments needed to accurately estimate true prevalence of MAP infection; as such, even estimates obtained using true prevalence should be interpreted with caution and considered when interpreting the results of this study. Sensitivity analysis provides a more robust understanding of the influence of this estimate, with herd costs ranging from $\$ 1,621$ (5\% prevalence) to $\$ 4,863$ (15\% prevalence).
Nearly $60 \%$ of the estimated annual herd cost $(\$ 1,889)$ resulted from reduced milk production in MAP-infected cows. It is well accepted that MAP infection is associated with a decrease in milk production (VanLeeuwen et al., 2002; Hendrick et al., 2005; Sorge et al., 2011b; McAloon et al., 2016); however, estimates tend to vary based on the stage of infection (Benedictus et al., 1987), parity (Wilson et al., 1993; McAloon et al., 2016), sampling and testing protocols (Tiwari et al., 2006), and the diagnostic accuracy of tests (Hendrick et al., 2005; McAloon et al., 2016). Two Canadian partial budget models estimating the annual cost of JD (Chi et al., 2002; Tiwari et al., 2008) assumed that milk production among MAP-infected cows did not decrease until the fourth lactation. Thus, lower estimates of the annual herd cost of reduced milk production were found compared with this study. This is primarily due to our consideration of reduced milk production in earlier parity groups. The milk loss estimates provided by Sorge et al. (2011b) showed significant milk losses in earlier lactations, and were considered most appropriate for this model, given they used recent, Canadian-specific data obtained using milk ELISA tests. These data, along 


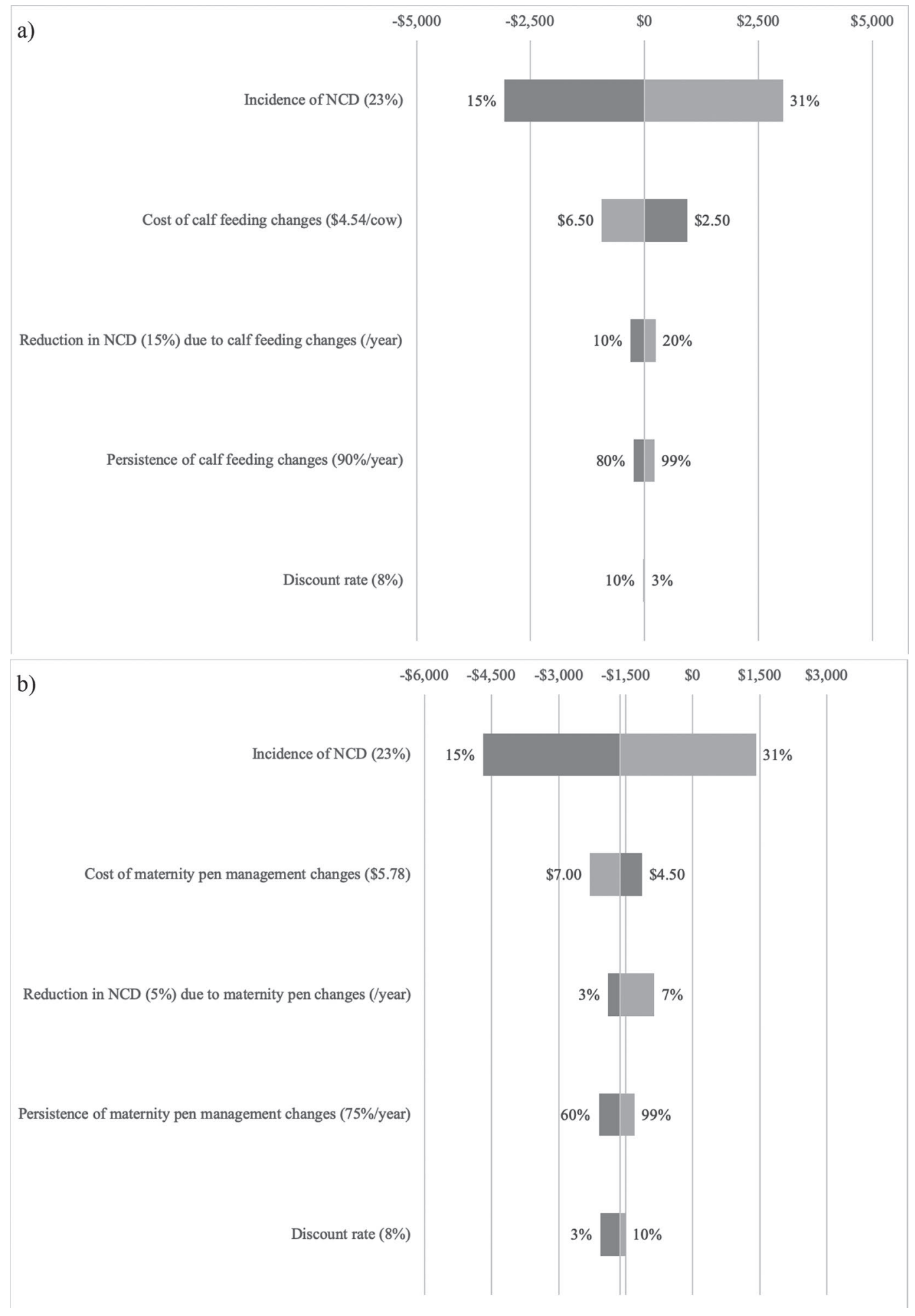

Figure 5. Tornado plot of the sensitivity of the net present value (NPV) of (a) calf feeding changes ( - Can $\$ 19.22$; where 1 Can $\$=0.823$ US\$ at the time of the study); (b) maternity pen management changes ( - Can\$1,629.67); and (c) maternity area structure changes (-Can\$701.03) to changes in the discount rate, incidence of neonatal calf diarrhea (NCD), and the cost, effect, and persistence of each management practice, assuming the farm is dealing with an incidence of NCD of $23 \%$ (i.e., no Johne's disease). 


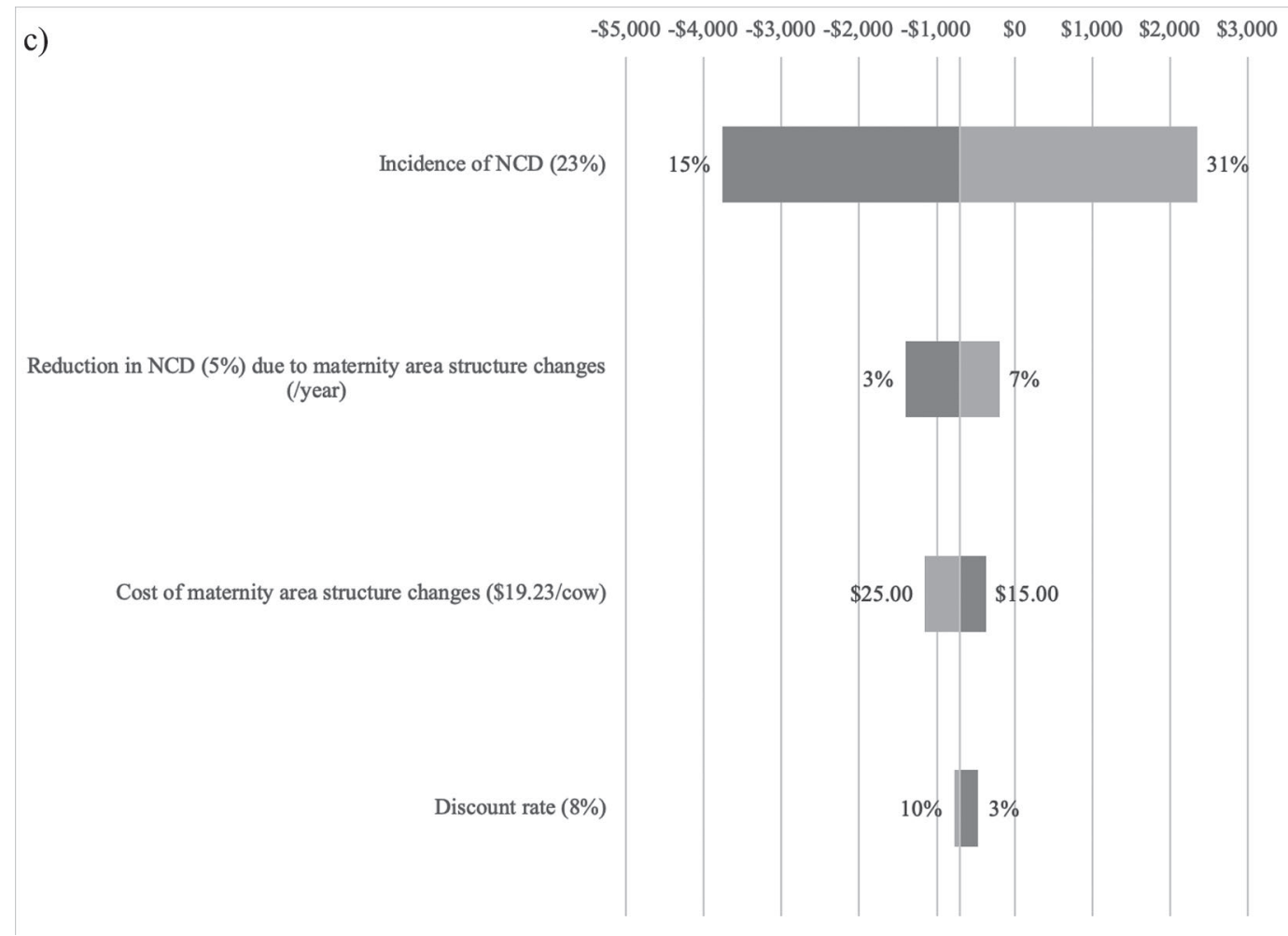

Figure 5 (Continued). Tornado plot of the sensitivity of the net present value (NPV) of (a) calf feeding changes ( - Can $\$ 19.22$; where 1 Can $\$=0.823$ US $\$$ at the time of the study); (b) maternity pen management changes ( - Can $\$ 1,629.67$ ); and (c) maternity area structure changes ( - Can $\$ 701.03$ ) to changes in the discount rate, incidence of neonatal calf diarrhea (NCD), and the cost, effect, and persistence of each management practice, assuming the farm is dealing with an incidence of NCD of $23 \%$ (i.e., no Johne's disease).

with data provided by Nielsen et al. (2002), allowed for a more realistic estimate of the average reduction in milk production among cows in each parity group.

The total herd cost of JD per cow estimated in this study (\$41.56) was lower than the per-cow costs reported in other Canadian economic assessments. Chi et al. (2002) reported a total cost of $\$ 49.24$ per cow for a 50-cow dairy herd with an apparent within-herd prevalence of $7 \%$, while Tiwari et al. (2008) reported a total cost of $\$ 49.05$ per cow for a 61 -cow dairy herd with an apparent prevalence of $12.7 \%$. Our findings fall within similar ranges to those published from the United States (Can $\$ 21$ to Can $\$ 43 /$ cow; Ott et al., 1999 ; Bhattarai et al., 2013) and the UK (Can $\$ 41.65 /$ cow; Gunn et al., 2004). Some of the primary differences observed relate to other models considering mortality and reproductive losses due to MAP infection, where our model did not. As McKenna et al. (2006) and Garcia and Shalloo (2015) note, research on the effect of JD on fertility, mortality, and predisposition to other diseases, such as mastitis, is inconsistent. Similar to reduced slaughter value, these findings are more likely to be attributed to clinical cases of JD. Given the low expected proportion of clinical cases in the context of Ontario, a decision was made to not monetize these losses. As a result, our estimate of the total annual herd costs of JD may be considered conservative.

Given the fecal-oral transmission of MAP, any onfarm management practice implemented to break this transmission cycle is likely to have positive effects on other diseases, most notably NCD (McKenna et al., 2006). The primary costs associated with NCD in dairy calves primarily relate to treatment costs and mortality due to NCD (Gunn, 2003). Although recent Ontario estimates were available for the incidence (Windeyer, 2013) and case fatality rate of NCD (Windeyer et al., 2014), a lack of estimates on the cost of treatment, mortality, feed costs, as well as the severity of NCD cases make accurate assumptions on the treatment costs difficult. With the assumptions provided, the annual herd cost of NCD for an average 78-cow dairy herd was estimated to be $\$ 1,390$ ( $\$ 36$ per heifer calf). Other estimates of the cost of NCD per calf vary (Gunn, 2003; Sischo et al., 1990), likely due to differences in geographic location, herd management, herd recruitment, and sampling procedures. Sensitivity analysis provided a better understanding of the robustness of estimates, with final estimates being most sensitive to incidence of 
NCD, average number of days treated, and the proportion of severe cases of NCD.

We assumed that producers considering on-farm changes for JD control would implement 1, 2, or all 3 of the management practices considered, resulting in 7 possible management scenarios. For those dealing with JD and NCD, all 7 strategies resulted in a positive NPV, with the most useful scenario being scenario 5, in which producers implemented changes to maternity area structure combined with calf feeding changes. The primary reason for the success of this scenario was the low cost for implementation, relative to the other management scenarios. Although changes to maternity area structure require a large upfront cost, the permanent nature of the change means no further costs are incurred and persistence of the change is $100 \%$. By combining these changes with calf feeding changes, which have the lowest recurrent costs, a moderate effect on JD, and a high effect on NCD, producers are able to keep their costs low. Interestingly, sensitivity analysis demonstrated that the costs of implementing nonpermanent changes (calf feed, maternity pen management) tended to be more influential on NPV than their corresponding effects on JD and NCD. However, the inverse was true for structural changes, where the effect was more influential. This further highlights the benefit of structural or permanent changes that correspond to a higher onetime investment, allowing benefits to accrue over time, as opposed to routine practices that require consistent working time to be expended to realize benefits.

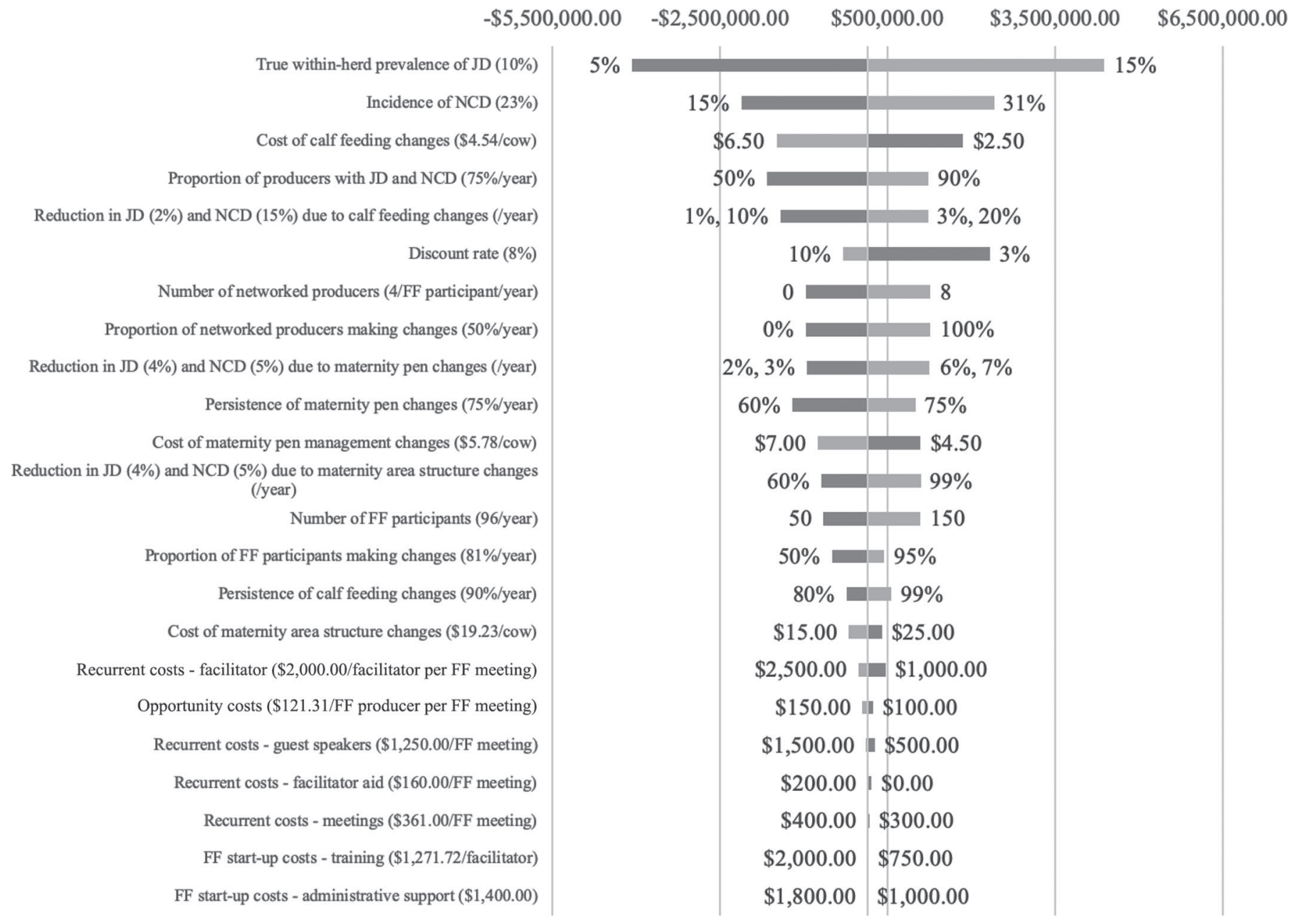

Figure 6. Tornado plot of the sensitivity of the net present value (NPV) of Ontario Focus Farm (FF) implementation over a 10-yr period (Can $\$ 149,861.73$; where 1 Can $\$=0.823$ US $\$$ at the time of the study) to changes in the discount rate; proportion of producers with Johne's disease (JD) and neonatal calf diarrhea (NCD); cost, persistence, and effect of each on-farm management change; number of FF participants; number of networked producers; proportion of networked producers making changes; proportion of FF participants making changes; proportion of those making changes implementing 2 changes; start-up, opportunity, and recurrent costs; true within-herd prevalence of JD; and incidence of NCD. 
Given that not all participants in FF will be dealing with JD on their farms, the NPV of each management scenario on farms dealing just with NCD was assessed. Interestingly, all 7 management strategies resulted in a negative NPV, suggesting that, although these practices do reduce the burden of NCD, the costs of the change outweigh the benefits. Recommendations for prevention of NCD typically focus on improved hygiene and quantity of colostrum feeding, as well as use of vaccination (Rossini, 2004; NADIS, 2014). Improved calf feeding changes were considered in this study and were expected to have a high impact on the incidence of NCD, which, when solely implemented, resulted in an NPV of $-\$ 19$. Sensitivity analysis suggested that positive net benefits were attainable if the incidence of NCD increased (i.e., a larger impact of implemented changes on calf health), costs of calf feeding were reduced, or their efficacy or persistence was improved. Therefore, ensuring that producers perform these behaviors consistently over time is a key factor in the realization of benefits. Overall, estimates on the cost-effectiveness of various implementation scenarios suggest that the adoption of multiple management changes proposed here is only beneficial if the farm is dealing with both JD and NCD.

The NPV of FF implementation was most sensitive to burden of disease (JD and NCD). A reduction in JD prevalence below $10 \%$, a reduction in NCD incidence below $23 \%$, or both led to a negative NPV. Conversely, JD and NCD morbidity above those values resulted in considerable gains. Another important and highly sensitive assumption was the proportion of producers that were assumed to be dealing with both JD and NCD on their farms. We assumed that, as the FF process was designed to address JD control specifically, the majority of producers implementing changes would be dealing with both JD and NCD. Importantly, sensitivity analysis revealed that a decrease in this proportion (from 75 to $50 \%$ of participants with JD and NCD) would result in $-\$ 1,661,090$ when veterinarian facilitators were used. The global sensitivity analysis further demonstrated this point, with NPV being significantly more sensitive to changes in disease status than program implementation parameters. Therefore, the success of the program is determined, in part, by the current burden of disease that exists on participants' farms. It would therefore be reasonable to recommend that only producers who are dealing with a high prevalence of JD (or NCD) should be considered for the program.

The most influential program component on program NPV was the network effect of participants. One of the goals of agricultural extension is to educate producers in the hopes that they will not only use that information to improve their own farm situation but relay that information to other producers throughout their own social networks (Andreata, 2001; Fisher, 2005). Each FF participant was expected to relay information about the change they had made to 2 other producers, $50 \%$ of whom were assumed to implement that same change. Sensitivity analysis demonstrated that a positive NPV is dependent upon network effects when there are fewer than 100 participants in a given year. Although a negative NPV would therefore be achieved if no nonparticipants adopted changes as a result of networking with participating producers, a positive NPV would easily be attained with an increase in participation. For example, an increase in the number of FF participants from $96 /$ yr to $150 /$ yr resulted in a NPV of $\$ 1,083,012$.

If all $\mathrm{FF}$ costs are passed on to the FF participants, then the cost would be nearly $\$ 300 /$ producer per meeting (using veterinarian facilitators). This cost is likely too high to attract much participation among producers. In addition, given that the reduction of prevalence of JD represents a positive not only for producers, but also for veterinarians, and the dairy industry in general, we suggest that an annual subsidy should be provided to implement the FF process. Investments from dairy industry organizations themselves, leveraged by provincial and federal government agencies, would be a reasonable expectation, given the importance of JD from an animal health, food safety, and consumer assurance perspective. The result of a $\$ 50,000$ annual subsidy for FF implementation would reduce the cost to roughly $\$ 160$ producer per meeting if using veterinarian facilitators. Ideally, the cost would be reduced to $\$ 100$ per producer per meeting (requiring a subsidy of $\$ 74,500$ ). Alternatively, non-veterinarian facilitators could be used to reduce this cost, in which case a $\$ 50,000$ subsidy would result in a cost of roughly $\$ 80 /$ producer per meeting. Although these subsidies would need to be considerably higher to scale this process in Ontario (to reach $\sim 3,500$ dairy producers), previous investments in Canada for JD control have been in the tens of millions (contributing to research, testing, producer support, and education). Given the positive economic case that is made for specific scenarios here, future investment in JD should consider this form of program.

\section{CONCLUSIONS}

The total annual herd cost of JD to an average Ontario dairy farm, with a true within-herd prevalence of $10 \%$, was estimated to be $\$ 3,242$. The total annual herd cost of NCD to an average Ontario dairy farm, with an incidence rate of $23 \%$, was estimated to be $\$ 1,390$. Implementation of various combinations of calf feeding changes, maternity pen management changes, and maternity area structure changes resulted in vary- 
ing net benefits in these simulations, depending on the presence of JD and NCD, the true burden of disease, and the specific management practices implemented. Overall, the implementation of the FF process over a $10-y r$ period yielded positive net benefits, suggesting that its implementation would be valuable for reducing the burden of JD and NCD on Ontario dairy farms.

\section{ACKNOWLEDGMENTS}

The authors thank the Ontario Ministry of Agriculture, Food and Rural Affairs and the University of Guelph for contributing funds for the completion of this work.

\section{REFERENCES}

Andreata, S. M. 2001. Learning from the group: A case study of the focus farm project in Gippsland, Victoria. MSc Thesis. University of Melbourne, Melbourne, Australia.

Benedictus, G., A. Dijkhuizen, and J. Stelwagen. 1987. Economic losses due to paratuberculosis in dairy cattle. Vet. Rec. 121:142-146.

Bhattarai, B., G. Fosgate, J. Osterstock, C. Fossler, S. Park, and A. Roussel. 2013. Perceptions of veterinarians in bovine practice and producers with beef cow-calf operations enrolled in the US Voluntary Bovine Johne's Disease Control Program concerning economic losses associated with Johne's disease. Prev. Vet. Med. 112:330-337.

Boardman, A., D. Greenberg, A. Vining, and D. Weiner. 2010. CostBenefit Analysis: Concepts and Practice. 4th ed. Prentice Hall, Upper Saddle River, NJ.

CanWest Dairy Herd Improvement Program (DHI). 2013. 2013 Annual Report/2014 Business Plan. Accessed July 16, 2018. http: //www.canwestdhi.com/pdf_files/DHI\%20annual\%20report\%20 2014.pdf.

Chi, J., J. A. VanLeeuwen, A. Weersink, and G. P. Keefe. 2002. Direct production losses and treatment costs from bovine viral diarrhoea virus, bovine leukosis virus, Mycobacterium avium subspecies paratuberculosis, and Neospora caninum. Prev. Vet. Med. 55:137-153.

Corbett, C. S., S. A. Naqvi, C. A. Bauman, J. De Buck, K. Orsel, F. Uehlinger, D. F. Kelton, and H. W. Barkema. 2018. Prevalence of Mycobacterium avium ssp. paratuberculosis infections in Canadian dairy herds. J. Dairy Sci. 101:11218-11228.

Dairy Farmers of Ontario (DFO). 2013. The Milk Producer-Ontario milk prices. December 2013 edition. Mississauga, Ontario, Canada. 89(12):42.

Dohoo, I., W. Martin, and H. Stryhn. 2009. Veterinary Epidemiologic Research. 2nd ed. VER Inc., Charlottetown, Prince Edward Island, Canada.

Dorshorst, N. C., M. T. Collins, and J. E. Lombard. 2006. Decision analysis model for paratuberculosis control in commercial dairy herds. Prev. Vet. Med. 75:92-122.

Ferrouillet, C., S. Wells, W. Hartmann, S. Godden, and J. Carrier. 2009. Decrease of Johne's disease prevalence and incidence in six Minnesota, USA, dairy cattle herds on a long-term management program. Prev. Vet. Med. 88:128-137.

Fisher, B. 2005. Implementing on-farm change on dairy farms using social networks to accelerate on-ground outcomes. Accessed July 16, 2018. http://www.regional.org.au/au/apen/2005/3/2758 fisherbl.htm.

Garcia, A. B., and L. Shalloo. 2015. Invited review: The economic impact and control of paratuberculosis in cattle. J. Dairy Sci. 98:5019-5039.

Groenendaal, H., M. Nielen, and J. W. Hesselink. 2003. Development of the Dutch Johne's disease control program supported by a simulation model. Prev. Vet. Med. 60:69-90.
Gulliksen, S. M., K. I. Lie, T. Loken, and O. Osteras. 2009. Calf mortality in Norwegian dairy herds. J. Dairy Sci. 92:2782-2795.

Gunn, A. 2003. Calf Scours in Southern Australia: A review of the impact of calf scours on beef enterprises. Final report for Meat and Livestock Australia. Sydney, New South Wales, Australia.

Gunn, G. J., R. W. Humphry, and A. W. Stott. 2004. Comparison of the modeled effects and consequential losses due to Johne's disease outbreaks for beef and dairy herds in Great Britain. Cattle Pract. $12: 1-5$.

Hendrick, S. H., D. F. Kelton, K. E. Leslie, K. D. Lissemore, M. Archambault, and T. F. Duffield. 2005. Effect of paratuberculosis on culling, milk production, and milk quality in dairy herds. J. Am. Vet. Med. Assoc. 227:1302-1308.

Idexx. 2013. Paratuberculosis milk test change to Idexx ELISA. Accessed Oct. 7, 2019. http://www.johnes.ca/pdf\%20files/JD\%20 milk\%20test\%20Change\%20to\%20IDEXX\%20ELISA\%20-\%20Oct $\% 202013$.pdf.

Lang, B. 2010. Dairy farm wage rates. Accessed August 26, 2013. http: //www.omafra.gov.on.ca/english/livestock/dairy/facts/wagerate htm

McAloon, C. G., P. Whyte, S. J. More, M. J. Green, L. O'Grady, A. Garcia, and M. L. Doherty. 2016. The effect of paratuberculosis on milk yield - A systematic review and meta-analysis. J. Dairy Sci. 99:1449-1460

McKenna, S. L. B., G. P. Keefe, A. Tiwari, J. A. VanLeeuwen, and H. W. Barkema. 2006. Johne's disease in Canada Part II: Disease impacts, risk factors and control programs for dairy producers. Can. Vet. J. 47:1089-1099.

Merkal, R. S., A. B. Larsen, and G. D. Booth. 1975. Analysis of the effects of inapparent bovine paratuberculosis. Am. J. Vet. Res. 36:837-838.

National Animal Disease Information Service (NADIS). 2014. Calf scours-Beef and dairy rearer units. Accessed July 16, 2018. http:// www.nadis.org.uk/bulletins/calf-scour-beef-and-dairy-rearer-units .aspx?altTemplate $=$ PDF.

Nielsen, S. S., H. Bjerre, and N. Toft. 2008. Colostrum and milk as risk factors for infection with Mycobacterium avium subspecies paratuberculosis in dairy cattle. J. Dairy Sci. 91:4610-4615.

Nielsen, S. S., C. Enevoldsen, and Y. T. Grohn. 2002. The Mycobacterium avium ssp. paratuberculosis ELISA response by parity and stage of lactation. Prev. Vet. Med. 54:1-10.

Ontario Johne's Disease Education and Management Assistance Plan (OJEMAP). 2013. Final OJEMAP results. Accessed July 16, 2018. http://johnes.ca/pdf\%20files/End\%20of\%20Program\%20Testing $\% 20$ Results.pdf.

Ontario Johne's Disease Education and Management Assistance Program (OJEMAP). 2009. Johne's education and management assistance program. Accessed July 16, 2018. http://www.johnes.ca/ pdf\%20files/Johnes\%20\%20Press $\% 20$ Release.pdf.

Ott, S. L., S. J. Wells, and B. A. Wagner. 1999. Herd level economic losses associated with Johne's disease on US dairy operations Prev. Vet. Med. 40:179-192.

Pillars, R. B., D. L. Grooms, C. A. Wolf, and J. B. Kaneene. 2009. Economic evaluation of Johne's disease control programs implemented on six Michigan dairy farms. Prev. Vet. Med. 90:223-232.

Pithua, P., L. A. Espejo, S. M. Godden, and S. J. Wells. 2013. Is an individual calving pen better than a group calving pen for preventing transmission of Mycobacterium avium subsp paratuberculosis in calves? Results from a field trial. Res. Vet. Sci. 95:398-404.

Pithua, P., S. M. Godden, S. J. Wells, and M. J. Oakes. 2009. Efficacy of feeding plasma-derived commercial colostrum replacer for the prevention of transmission of Mycobacterium avium ssp. paratuberculosis in Holstein calves. J. Am. Vet. Med. Assoc. 234:1167-1176.

Quigley, J. 2014. Cost of feeding milk replacer. Accessed on July 16, 2018. http://www.progressivedairy.com/pd/features/2008/0208/ 0208_quigley.html.

Roche, S. M. 2014. Investigating the role of agricultural extension in influencing Ontario dairy producer behavior for Johne's disease control. PhD Thesis. University of Guelph, ON, Canada. Accessed Jan. 7, 2019. https://atrium.lib.uoguelph.ca/xmlui/handle/ $10214 / 8125$. 
Roche, S. M., A. Jones-Bitton, M. Meehan, M. Von Massow, and D. F. Kelton. 2015. Evaluating the effect of Focus Farms on Ontario dairy producers' knowledge, attitudes, and behavior toward control of Johne's disease. J. Dairy Sci. 98:5222-5240.

Rossini, K. 2004. Effects of calfhood respiratory and digestive disease on calfhood morbidity and first lactation production and survival rates. MSc Thesis. Virginia Polytechnic Institute and State University, Blacksburg, VA.

Sischo, W. M., D. W. Hird, I. A. Gardner, W. M. Utterback, K. H. Christiansen, T. E. Carpenter, C. Danaye-Elmi, and B. R. Heron. 1990. Economics of disease occurrence and prevention on California dairy farms: A report and evaluation of data collected for the National Animal Health Monitoring System, 1986-87. Prev. Vet. Med. 8:141-156.

Sorge, U., D. Kelton, K. Lissemore, A. Godkin, S. Hendrick, and S. Wells. 2010. Attitudes of Canadian dairy farmers toward a voluntary Johne's disease control program. J. Dairy Sci. 93:1491-1499.

Sorge, U. S., K. Lissemore, A. Godkin, S. Hendrick, S. Wells, and D. Kelton. 2011b. Associations between paratuberculosis milk ELISA result, milk production, and breed in Canadian dairy cows. J. Dairy Sci. 94:754-761.

Sorge, U. S., K. Lissemore, A. Godkin, J. Jansen, S. Hendrick, S. Wells, and D. F. Kelton. 2011a. Changes in management practices and apparent prevalence on Canadian dairy farms participating in a voluntary risk assessment-based Johne's disease control program. J. Dairy Sci. 94:5227-5237.

Svensson, C., K. Lundborg, U. Emanuelson, and S. Olsson. 2003. Morbidity in Swedish dairy calves from birth to 90 days of age and individual calf-level risk factors for infectious diseases. Prev. Vet. Med. 58:179-197.

Sweeney, R. W., M. T. Collins, A. P. Koets, S. M. McGuirk, and A. J. Roussel. 2012. Paratuberculosis (Johne's Disease) in Cattle and Other Susceptible Species: ACVIM Consensus Statement. J. Vet. Intern. Med. 26:1239-1250.

Tiwari, A., J. A. VanLeeuwen, I. R. Dohoo, G. P. Keefe, J. P. Haddad, H. M. Scott, and T. Whiting. 2009. Risk factors associated with Mycobacterium avium subspecies paratuberculosis seropositivity in Canadian dairy cows and herds. Prev. Vet. Med. 88:32-41.

Tiwari, A., J. A. VanLeeuwen, S. L. B. McKenna, G. P. Keefe, and H. W. Barkema. 2006. Johne's disease in Canada: Part I: Clinical symptoms, pathophysiology, diagnosis, and prevalence in dairy herds. Can. Vet. J. 47:874-882.
Tiwari, A., J. A. vanLeeuwen, I. R. Dohoo, G. P. Keefe, and A. Weersink. 2008. Estimate of the direct production losses in Canadian dairy herds with subclinical Mycobacterium avium subspecies paratuberculosis infection. Can. Vet. J. 49:569-576.

Trotz-Williams, L. A., S. Wayne Martin, K. E. Leslie, T. Duffield, D. V. Nydam, and A. S. Peregrine. 2007. Calf-level risk factors for neonatal diarrhea and shedding of Cryptosporidium parvum in Ontario dairy calves. Prev. Vet. Med. 82:12-28.

VanLeeuwen, J. A., G. P. Keefe, and A. Tiwari. 2002. Seroprevalence and productivity effects of infection with bovine leukemia virus, Mycobacterium avium subspecies paratuberculosis, and Neospora caninum in maritime Canadian dairy cattle. Bovine Pract. 6:86-91.

Waltner-Toews, D., S. W. Martin, A. H. Meek, and I. McMillan. 1986. Dairy calf management, morbidity and mortality in Ontario Holstein herds. I. The data. Prev. Vet. Med. 4:103-124.

Wells, S. J., L. P. Garber, and G. W. Hill. 1997. Health status of preweaned dairy heifers in the United States. Prev. Vet. Med. 29:185-199.

Wilson, D. J., C. Rossiter, H. R. Han, and P. M. Sears. 1993. Association of Mycobacterium paratuberculosis infection with reduced mastitis, but with decreased milk production and increased cull rate in clinically normal dairy cows. Am. J. Vet. Res. 54:1851-1857.

Windeyer, C. 2013. Vaccination and risk factors for bovine respiratory disease in dairy heifer calves. PhD Thesis, University of Guelph, ON, Canada.

Windeyer, M. C., K. E. Leslie, S. M. Godden, D. C. Hodgins, K. D. Lissemore, and S. J. LeBlanc. 2014. Factors associated with morbidity, mortality, and growth of dairy heifer calves up to 3 months of age. Prev. Vet. Med. 113:231-240.

\section{ORCIDS}

S. M. Roche () https://orcid.org/0000-0001-6934-6497

D. Renaud () https://orcid.org/0000-0002-3439-3987

D. A. Shock () https://orcid.org/0000-0003-0796-6820

A. Jones-Bitton (®) https://orcid.org/0000-0002-4933-3688

D. F. Kelton @ https://orcid.org/0000-0001-9606-7602 